\title{
Effect of uniaxial compressive loading on gas permeability and chloride diffusion coefficient of concrete and their relationship
}

A. DJERBI TEGGUER ${ }^{\mathrm{a}, *}$, S. BONNET ${ }^{\mathrm{b}}$, A. KHELIDJ ${ }^{\mathrm{b}}$, V. BAROGHEL-BOUNY ${ }^{\mathrm{a}}$

${ }^{a}$ Institut français des sciences et technologies des transports, de l'aménagement et des réseaux, 58 Bd Lefebvre, F-75732 Paris Cedex 15, France

Tel (33) 1-40-43-51-65 Fax (33) 1-40-43-54-98

${ }^{b}$ GeM (UMR CNRS 6183) Institut de Recherche en Génie Civil et Mécanique IUT de Saint-Nazaire, 58 rue Michel Ange, B.P. 420, F-44606 Saint-Nazaire Cedex- France

\section{ABSTRACT}

11 Knowledge of the transport properties of damaged concrete in marine environments is essential for predicting its durability. The objective of this study was to fill this gap by correlating the change in permeability and chloride diffusivity with an increasing uniaxial load on ordinary concrete (OC) and high performance concrete (HPC). Concrete cylinders were induced microcracks by mechanical uniaxial compression between $60 \%$ and $90 \%$ of the ultimate strength to get diffuse damage. The damage variable of specimens was evaluated by elastic stiffness degradation and ultrasound pulse velocity. After unloading intrinsic gas permeability was measured using a constant head permeameter, the chloride migration coefficient was evaluated by migration test in steady state conditions, with the same concrete specimen. The damage variable of specimens showed correlation with gas permeability and chloride diffusion of concrete in this experiment. A linear correlation was obtained between intrinsic permeability coefficient and chloride diffusion coefficient depending on the damage variable, specific for each concrete type (OC and HPC).

\section{Keywords:}

Diffuse damage, Damage variable, Chloride Diffusion, Durability, Microcracks, Gas Permeability, High performance concrete, Time lag.

\footnotetext{
${ }^{*}$ Corresponding author. Tel.: +33-1-40-43-51-65; Fax: +33-1-40-43-54-98.

E-mail address: assia.tegguer@ifsttar.fr (A. Djerbi Tegguer).
} 


\title{
Effect of uniaxial compressive loading on gas permeability and chloride diffusion coefficient of concrete and their relationship
}

\author{
A. DJERBI TEGGUER ${ }^{\mathrm{a}, *}$, S. BONNET ${ }^{\mathrm{b}}$, A. KHELIDJ ${ }^{\mathrm{b}}$, V. BAROGHEL-BOUNY $^{\mathrm{a}}$ \\ ${ }^{a}$ Institut français des sciences et technologies des transports, de l'aménagement et des réseaux, \\ 58 Bd Lefebvre, F-75732 Paris Cedex 15, France \\ Tel (33) 1-40-43-51-65 Fax (33) 1-40-43-54-98 \\ ${ }^{b}$ GeM (UMR CNRS 6183) Institut de Recherche en Génie Civil et Mécanique IUT de Saint-Nazaire, \\ 58 rue Michel Ange, B.P. 420, F-44606 Saint-Nazaire Cedex- France
}

\section{Introduction}

Predictions of service life for both new and existing concrete structures has assumed increasing importance as the incidence of damage due to reinforcement corrosion increases. Sustainability indicators of concrete such as permeability and diffusion are the main transport properties for concrete, because it governs the ingress of water, oxygen, carbon dioxide, and chlorides which are necessary for the electro-chemical reaction of corrosion. Extensive work has been carried on over the past decades to understand transport properties of concrete, and numerous service life prediction models have been introduced. The disadvantage of these models is that all predictions are carried out considering a perfect, uncracked concrete [2-4]. Concrete structures near marine environments are subjected to a combination of chloride and load resulting in both macro and microcracking. The presence of cracks can significantly modify these transport properties of concrete. Microcracks that are discrete and well distributed will influence transport properties in very different manner compared to visible connected localized macrocracks [5-18]. In the case of localized damage it has been shown that gas permeability of concrete measured on disks fractured using a splitting tensile test increases with crack opening displacement COD cubed [5]. Concerning chloride diffusion

\footnotetext{
${ }^{*}$ Corresponding author. Tel.: +33-1-40-43-51-65; Fax: +33-1-40-43-54-98. E-mail address: assia.tegguer@ifsttar.fr (A. Djerbi Tegguer).
} 
measured by migration test, a linear variation was obtained between the diffusion coefficient through the crack and crack width, this coefficient was not dependent on material parameters and becomes constant when the crack width was higher than $80 \mu \mathrm{m}$, its value is the diffusion coefficient of chloride in a free solution [9].

In comparison, the studies of diffuse damage obtained by compression load have shown a marked threshold effect which called percolation threshold, regardless of concrete studied and the experimental protocol adopted to measure the transport properties and crack of concrete [10-18]. If the crack network is not connected, these transport properties are related to the concrete itself, such as the porosity of concrete and interconnectivity of the pore system. Beyond the percolation threshold cracked concrete its related to crack properties, the gas permeability changes very significantly with the increase of damage level: an increase in permeability with several orders of magnitude for damaged concrete can be observed $[8,10-$ $13,18]$, while chloride penetration is much less affected by cracks [14-17].

Existing experimental data provide some correlation between the material degradation and the permeability of concrete. The studies done by Picandet et al.[12] and Zhou et al.[18] show a correlation between the gas permeability and damage variable evaluated from uniaxial compression test. Moreover very little data are available on the relationship between permeability and chloride diffusion of concrete damaged by uniaxial compressive loading. The real contribution of this work is to investigate simultaneously the altered diffusivity and the altered permeability by uniaxial damage in order to find the correlation between these two parameters: chloride diffusion coefficient and the gas permeability. This correlation will be established by introducing damage variable resulting from a reduction in stiffness of the concrete damaged by sustained uniaxial loading to get diffuse damage. One objective of this research was conducted to achieve further information on the influence of microcracks on the gas permeability and chloride diffusion of ordinary concrete (OC) and high performance 
(HPC). Concrete cylinders were loaded under uniaxial compression between $60 \%$ and $90 \%$ of the ultimate strength. The time of sustained load is $2 \mathrm{~h}$ for each load level, added $1 \mathrm{~h}$ and 30 min for high load level. A damage variable can be obtained by static and dynamic method. After unloading intrinsic gas permeability was measured using a constant head permeameter, the chloride migration coefficient was evaluated by migration test in steady state conditions, with the same concrete specimen. These measurements allow the comparison between chloride diffusion and gas permeability for similar concrete at similar load levels.

\section{Experimental program}

\subsection{Specimen Preparation}

Two concrete mixes were made with the same cement CPA-CEM I 52.5: one ordinary concrete (OC) with a water/cement ratio of 0.49 and high performance with a water/cement ratio of 0.32 (HPC), (see Table 1). Concrete cylinders of length $22 \mathrm{~cm}$ and diameter $11 \mathrm{~cm}$ were prepared from a single batch for each mix. The concrete mixtures were cast in steel molds and compacted using a mechanical vibrator. After casting the cylindrical specimens were stored in a room maintained at $20^{\circ} \mathrm{C}$ and about $95 \%$ relative humidity (RH) for 24 hours, and were cured in water at $20^{\circ} \mathrm{C}$ for 1 year. They were stored in air-conditioned room $\left(20^{\circ} \mathrm{C}\right.$ and RH $50 \pm 5 \%$ ) until testing. The characteristics of these concretes ageing 1 year are shown in Table 2. The open porosity was measured by water saturation.

All concrete specimens were tested under an axial compressive loading condition (see Fig. 1.). After unloading concrete discs of $5 \mathrm{~cm}$ in thickness were cut off from the central portion of the cylindrical specimens with a diamond blade saw (see Fig. 2.). These discs were sealed with two epoxy resin coats in order to ensure one-dimensional gas and chloride flow through the discs. Drying the discs before proceeding to any gas permeability test is necessary $[12,13,18,19,20]$. In this study, all disc specimens are oven-dried at $60^{\circ} \mathrm{C}$ to constant weight. 
107 This procedure has taken 2 months for OC and 3 months for HPC. Then, they are cooled for

$10848 \mathrm{~h}$ in a desiccator at $20^{\circ} \mathrm{C}$ before being tested.

109 The concrete sample preparation such as cutting and drying can affect the microstructure of

110 concrete. However this additional damage does not affect the evolution of transport properties

111 versus uniaxial damage, since the same additional damage was applied on the concrete sample

112 for each damage level.

113 After permeability test the concrete samples were then vacuum saturated in order to measure

114 the chloride diffusion. These were placed in vacuum container with a $2.5 \mathrm{kPa}$ pressure for $4 \mathrm{~h}$.

115 Then, with the vacuum pump still running, the container was filled with water saturated with

$116 \mathrm{NaOH}(0.025 \mathrm{~mol} / \mathrm{l})$ and $\mathrm{KOH}(0.083 \mathrm{~mol} / \mathrm{l})$ in order to immerse the specimen. The samples

117 were saturated with alkaline salt solutions to prevent leaching of concrete. The vacuum was

118 maintained for $24 \mathrm{~h}$ before allowing the air to enter into the container [21]. After this 119 saturation procedure, chloride migration test was driving on damaged and undamaged 120 concrete.

121

122

123

124

125

126

127

\subsection{Uniaxial damage}

Concrete cylinders were tested under uniaxial compression between $60 \%$ and $90 \%$ of the ultimate strength measured at 1 year called $\mathrm{f}_{\mathrm{c}}$ (see Table 2). An hydraulic press of $2400 \mathrm{kN}$ capacity was used for this test. On each cylinder, the longitudinal strain is measured using an extensometer cell equipped with three linear variable displacement transducers (LVDT), with a range agreeing within $0.5 \mathrm{~mm}$ and an accuracy of $1 \mu \mathrm{m}$, (see Fig. 1.). The transducers are laid every $120^{\circ}$ intervals to take into account any asymmetric longitudinal strain. The concrete cylinders were loaded progressively for predetermined load levels. Each load level was being sustained for varying periods up to two hours [22]. The short duration of tests was required to avoid the broken of measurement system in the case of high load level $\left(90 \% \mathrm{f}_{\mathrm{c}}\right)$. These displacements are recorded during the loading and unloading phase until the recovery was 
negligible. The average longitudinal displacement is calculated with the three LVDT

134 measurements.

135 The data required for the assessment of the mechanical properties consists of the axial stress

136 and longitudinal strain. The evaluation of the variation of elasticity modulus is used to

137 calculate damage variable which is an indication of the degree of microcracking. A damage

138 parameter $\mathrm{d}$ in damage mechanics can be defined from relative ratio of modulus in elasticity

139 [23], as in Eq. (1):

$$
\mathrm{d}=\frac{E_{0}-E}{\mathrm{E}_{0}}
$$

140 Where $\mathrm{E}_{0}$ is the initial modulus of elasticity (Table 2), and $\mathrm{E}$ is the final modulus of elasticity

141 obtained for damaged concrete.

142 The modulus of elasticity can be determined by a static and dynamic evaluation. The static

143 modulus of elasticity is usually calculated with (strength-strain) curve from a plastic-

144 fracturing model [24]. Before each stress level, the initial modulus of elasticity of each

145 cylinder was obtained with the slope of the loading curve calculated from $5 \%$ to $30 \%$ of the

146 ultimate strength. The final modulus of elasticity for damaged concrete is calculated with the

147 unloading curve also from 5\% to $30 \%$ of the ultimate strength. .

148 The dynamic modulus of elasticity of concrete can be determined non destructively using

149 resonance tests based on measuring the fundamental flexural and torsional frequencies of

150 concrete specimens using a 'Grindosonic' apparatus [25]. This last were carried out on

151 concrete cylinders before loading to obtain $\mathrm{E}_{0}$ and immediately after unloading to obtain $\mathrm{E}$.

152

153

154

155

156

\subsection{Gas permeability test procedure}

An apparatus known as the CEMBUREAU permeameter was used for the determination of permeability [26]. This is a constant head permeameter and nitrogen gas is used as the permeating medium. A pressure difference up to $0.3 \mathrm{MPa}$ can be applied to the specimens in 
the pressure cells which are sealed by a tightly fitting polyurethane rubber pressing under high

158 pressure $(0.7 \mathrm{MPa})$ against the curved surface. Permeability measurements were made in an

159 air-conditioned room $\left(20 \pm 1^{\circ} \mathrm{C}\right.$ and $\left.\mathrm{RH} 50 \pm 5 \%\right)$. Each disc was tested with five differential

160 pressures: $0.05,0.1,0.15,0.2$ and $0.3 \mathrm{MPa}$. The volume flow rate through the specimens is

161 measured by means of a soap bubble flow meter. After initiating the percolation of nitrogen

162 through a specimen at a given applied pressure, sufficient time (varying from 40 minutes to

163 several hours) is provided for the establishment of steady state flow before an actual

164 measurement is taken. This condition is verified by taking two measurements separated by a

16515 minute time interval. If the two values differ by less than $3 \%$, a steady state flow condition

166 is assumed to be achieved.

167 The apparent coefficient of permeability $\mathrm{k}_{\mathrm{A}}\left(\mathrm{m}^{2}\right)$ is calculated from the Hagen-Poiseuille expression Eq. (2) for laminar flow of a compressible fluid through a porous body under steady state conditions [27].

$$
\mathrm{k}_{\mathrm{A}}=\frac{\mathrm{Q}}{\mathrm{A}} \frac{2 \mu \mathrm{L} \mathrm{P}_{\mathrm{atm}}}{\left(\mathrm{P}_{\mathrm{i}}^{2}-\mathrm{P}_{\mathrm{atm}}^{2}\right)}
$$

170 Where $\mathrm{L}$ is the thickness of the sample $(\mathrm{m}), \mathrm{A}$ is the cross-sectional area $\left(\mathrm{m}^{2}\right)$, Q is the gas

171 flow $\left(\mathrm{m}^{3} / \mathrm{s}\right), \mu$ is the coefficient of viscosity $\left(1.78 .10^{-5} \mathrm{~Pa} . \mathrm{s}\right.$ for nitrogen gas at $\left.20^{\circ} \mathrm{C}\right), \mathrm{P}_{\mathrm{i}}$ is the 172 applied absolute pressure or inlet pressure $(\mathrm{Pa})$, and $\mathrm{P}_{\mathrm{atm}}$ is the atmospheric pressure $(\mathrm{Pa})$.

173 In fact, the gas percolation through a fine porous body like concrete, can be regarded as 174 resulting from two flow modes: viscous flow and slip flow or Knudsen flow. Various methods

175 for the calculation of non-viscous flow exist. The most widely used is the relation proposed 176 by Klinkenberg Eq. (3) introducing the concept of an intrinsic coefficient of permeability $\mathrm{k}_{\mathrm{V}}$ 177 relative to viscous flow only [28].

$$
\mathrm{k}_{\mathrm{A}}=\mathrm{k}_{\mathrm{V}}\left(1+\frac{\mathrm{b}}{\mathrm{P}_{\mathrm{m}}}\right)
$$


178 Where $\mathrm{P}_{\mathrm{m}}$ is mean gas pressure, $\mathrm{P}_{\mathrm{m}}=\left(\mathrm{P}_{\mathrm{i}}+\mathrm{P}_{\mathrm{atm}}\right) / 2$, $\mathrm{b}$ is the Klinkenberg coefficient (Pa) which is function of the porous body and the infiltrated gas, and $\mathrm{k}_{\mathrm{V}}$ is the limiting value of gas permeability when the mean pressure $\mathrm{P}_{\mathrm{m}}$ tends towards infinity. The method of

181 determination of $\mathrm{k}_{\mathrm{V}}$ consists in measuring $\mathrm{k}_{\mathrm{A}}$ at different pressures $\left(\mathrm{P}_{\mathrm{i}}\right)$ and plotting it against 182 the inverse of the mean pressure $\left(1 / \mathrm{P}_{\mathrm{m}}\right)$. The slope of the line leads to the empirical 183 Klinkenberg coefficient $\mathrm{b}$ and the origin leads to the intrinsic permeability.

\subsection{Steady state migration test}

Since diffusion experiments are time-consuming, steady state migration tests were developed to accelerate chloride ions through the concrete [29-31]. Each specimen is placed between the two compartments of a cell where flat silicone circular seals ensure that the system is leaktight (Fig. 3.). The solutions were made with $\mathrm{NaOH}(0.025 \mathrm{~mol} / \mathrm{l})+\mathrm{KOH}(0.083 \mathrm{~mol} / \mathrm{l})$ in upstream and downstream compartment. $\mathrm{NaCl}(0.513 \mathrm{~mol} / \mathrm{l})$ was added in the upstream solution. A $12 \mathrm{~V}$ was applied between the sides of the concrete sample and the test was carried out at temperature $\mathrm{T}=20 \pm 5^{\circ} \mathrm{C}$. The downstream solution was titrated with silver nitrate $(0.05 \mathrm{M})$. As the flux becomes constant, Nernst-Planck's relation allows to deduce the value of the diffusion coefficient, as seen in Eq. (4):

$$
\mathrm{J}(\mathrm{x})=-\mathrm{D}_{\mathrm{e}} \frac{\partial \mathrm{c}}{\partial \mathrm{x}}+\mathrm{D}_{\mathrm{e}} \frac{\mathrm{zFe}}{\mathrm{RTL}} \mathrm{c}+\mathrm{cv}(\mathrm{x})
$$

where $D_{e}$ is the diffusion coefficient of concrete $\left(\mathrm{m}^{2} / \mathrm{s}\right), \mathrm{c}$ is the chloride concentration of the upstream compartment $\left(\mathrm{mol} / \mathrm{m}^{3}\right)$ assumed to be constant, $\mathrm{J}(\mathrm{x})$ is the flux of chloride ions $\left(\mathrm{mol} /\left(\mathrm{m}^{2} \mathrm{~s}\right)\right), \mathrm{z}$ is the chloride ion valency $(\mathrm{z}=1), \mathrm{F}$ is the Faraday constant $(\mathrm{F}=96480$ $\mathrm{J} /(\mathrm{V} . \mathrm{mol})), \mathrm{e}$ is the actual potential drop between the surfaces of specimen $(\mathrm{V}), \mathrm{R}$ is the gas constant $(\mathrm{R}=8.3144 \mathrm{~J} /(\mathrm{mol} . \mathrm{K})), \mathrm{T}$ is the absolute temperature $(\mathrm{K})$ and $v(\mathrm{x})$ is the velocity of the solute $(\mathrm{m} / \mathrm{s})$. If the concrete is saturated, the velocity of the solute can be neglected. Since the potential drop is $\geq 10 \mathrm{~V}$, ions migrate as a result of the electrical field rather than of the 
concentration gradient. This ensures that the diffusion flow can be neglected in the

203 experiments as shown by Andrade [29]. Eq. (4) can be simplified and then Eq. (5) is obtained:

$$
\mathrm{D}_{\mathrm{e}}=\frac{\mathrm{L}}{\mathrm{c}} \frac{\mathrm{RT}}{\mathrm{zFe}} \mathrm{J}
$$

204 To establish a steady state, the concentration gradient must be constant during the test.

205 Therefore we have to renew the upstream and downstream solutions frequently. The evolution 206 of current during testing showed a small increase at the beginning of the test and then a 207 stabilisation for all concretes.

\section{Results and discussion}

\subsection{Effect of uniaxial damage on the strain results}

Strain is the first criterion for damage evaluation of concrete. For each load level maximal strain $\varepsilon_{\max }$ under loading and residual strain $\varepsilon_{\text {res }}$ which was recorded 30 min after unloading were evaluated. Figure 4 presents the evolution of maximal strain $\varepsilon_{\max }$ versus load level. The

214 results put in evidence that the maximal strain obtained at 2 hours increased regularly with the 215 level of applied load for both concretes. This might be explained by the development of 216 internal microcracking of concrete. It was generally accepted that cracking of concrete 217 subjected to compressive loading may take the form of one of the following three ways: bond 218 cracks, mortar cracks and aggregate cracks. Bond cracks are the microcracks in the interfacial 219 transition zone (ITZ) between the cement paste and aggregate. In facts bond cracks may 220 develop even before any loading is placed on the concrete due to settlement of fresh concrete, 221 hydration of cement paste, drying shrinkage and carbonation shrinkage. Mortar cracks are 222 microcracks which can be found in the matrix between aggregates. Theses cracks begin after 223 the bond cracks have started and it is these type of cracks that lead the failure of concrete. As 224 the load increases they begin to propagate throughout the matrix extensively combining with 225 other mortar cracks as well as bond cracks. Aggregates cracks are cracks formed through the 226 aggregate. 
Compressive load below $30 \% \mathrm{f}_{\mathrm{c}}$ will not cause microcracks and the concrete behave as an

228 elastic material. At $30 \% \mathrm{f}_{\mathrm{c}}$ to $60 \% \mathrm{f}_{\mathrm{c}}$ the bond cracks increase in length, width and number as

229 the load increases (as reported in $[17,32]$ ). However at $60 \% \mathrm{f}_{\mathrm{c}}$ and above the crack system

230 becomes unstable and causes the strain to increase. In addition to bond cracking, mortar

231 microcraking begins to become interconnected and form "continuous cracks" as classified by

232 Shah et al. [33]. At $90 \% \mathrm{f}_{\mathrm{c}}$ the maximal strain increased with the increase of the time load.

233 This might be explained by the increase of the crack size due to the expansion of the cylinder

234 and the increase of longitudinal displacement. This evolution confirms that the cracking

235 pattern is developing during the loading phase only.

236 Microcracking was investigated by a videomicroscope with 200 times magnification and an

237 oblique light was used to observe the cross section of the most damaged discs (see Figure 5).

238 Crack width and length are than smaller than $3 \mu \mathrm{m}$ and $6 \mathrm{~mm}$, respectively. The specimens of

239 OC and HPC group show clearly different crack. In OC cracking takes place in the ITZ and

240 mortar; however HPC does not develop significant bond cracks than in corresponding of OC.

241 This may be partially explained by the elimination of the region of connected pores that were

242 a common feature of the ITZ of OC, but also confirms the improvement of the strength of the

243 interfacial zone in the HPC. HPC has a lower w/c, resulting in stronger cement paste. As a

244 consequence, high strength concrete has stronger interfacial zone, which is due to a reduction

245 in excess bleeding. This leads the development of aggregate cracks in HPC. It is presumed

246 that these aggregates experienced in previous study leading to a mode of fracture analogous to

247 that which occurs in a splitting tensile test [9].

248 The residual strain $\varepsilon_{\text {res }}$ evaluated after unloading increase linearly with the increase of

249 maximal strain $\varepsilon_{\max }$ for both concretes (see Figure 6). The microcracking patterns varied

250 among the mixes for each load level the maximal strain under loading of HPC is higher than

251 OC but the residual strain is lower. This implies a partial closure of the microcracks of HPC 
concrete after unloading which is due to a more elastic response of HPC than OPC (see Table

253 2). This results can also be interpreted by the development of combined cracks, consisting of 254 combinations of bond and mortar cracks, which is significant in OC than HPC (as observed 255 by Carrasquilio [34] and Nemati [35]). This can be attributed to the fact that HPC is more 256 brittle than OC. As a result, when fracture occurs in HPC, the crack propagation is associated 257 with less combination of bond and mortar cracks.

\subsection{Increase permeability versus strain}

The results put in evidence that the intrinsic permeability coefficient $\mathrm{k}_{\mathrm{V}}$ of OC and HPC increased with the increase of the residual strain, and HPC $\mathrm{k}_{\mathrm{V}}$ values were lower than the OC values (Figure 7). This might be explained by the progressive change in the internal structure of the specimen due to the increasing of load level. Concrete is a capillary porous material and its permeability is closely related to its microstructure. The HPC porosity is lower than OC porosity (see Table 2) and thus the HPC gas permeability is lower than OC permeability, the average $\mathrm{k}_{\mathrm{V}}$ values for the virgin specimen, were $2,5710^{-17} \mathrm{~m}^{2} / \mathrm{s}$ for OC and $1,1110^{-17} \mathrm{~m}^{2} / \mathrm{s}$ for HPC. Once there are micro cracks in the concrete caused by uniaxial damage, there would also be favourable passages for gas flow, This can be explained by the gas flow through the pores and additionally through cracks in the case of cracked concrete. Therefore, higher residual strain would result in higher gas permeability as obtained in figure 7 .

\subsection{Relationship between increase in gas permeability and damage value}

The damage coefficient, $d$, which is a measure of the stiffness degradation, can be calculated using (Eq. 1). For these load levels $\left(60 \% \mathrm{f}_{\mathrm{c}}\right.$ to $\left.90 \% \mathrm{f}_{\mathrm{c}}\right)$, damage coefficients approximately from 0.015 to 0.16 were obtained (see Figure 8 ). The damage coefficient of OC and HPC increased with the increase of the load levels; this is due to the applied load which produces the degradation in the materials shown by a continuous reduction in the elastic modulus and 
appearance of the residual strain. The damage coefficient evaluated by static or dynamic method of OC is higher than HPC for the same load level. This result confirms that the microcracking patterns of OC is more significant than HPC. There is a relationship between the damage variable measured by the static method and that measured by the dynamic method with a correlation coefficient $\mathrm{R}^{2}=0.95$ (Figure 8). This linear relationship shows that the 283 damage obtained by the dynamic method is slightly higher than that obtained by the static 284 method. This linear trend which is non material dependent should be confirmed with others 285 cementious materials before being used to get damage rate with this very useful non destructive technique.

The relative permeability of cracked concrete $k_{v}(d) / k_{v 0}$ is defined as the ratio between the permeability coefficient of cracked concrete $\mathrm{k}_{\mathrm{v}}(\mathrm{d})$ and the permeability coefficient of uncracked concrete $k_{v 0}$. It can be related to the damage variable " $d$ ". The increase in permeability relative permeability $\mathrm{k}_{\mathrm{v}}(\mathrm{d}) / \mathrm{k}_{\mathrm{v} 0}$ with the damage coefficient evaluated by dynamic method is illustrated in Figure $9 . \mathrm{k}_{\mathrm{v}}(\mathrm{d}) / \mathrm{k}_{\mathrm{v} 0}$ tended to increase slightly beyond the damage coefficient of 0,03 for both concretes. This range of damage coefficient corresponds to the 293 observed load level which was found $70 \% \mathrm{f}_{\mathrm{c}}$ for OC and HPC. An exponential curve for the 294 relative increase of gas permeability was obtained as a function of damage coefficient. A 295 similar relation was obtained by Picandet et al. [12] using cyclic compression test. This 296 relation was obtained on the range of $d<0.15$. However, with the increase of damage, $d>$ 297 0.15, different relations should be adopted for homogenous crack pattern and fracture298 dominating pattern otherwise the impact of damage extent on permeability increase can be 299 overestimated [18].

\subsection{Effect of uniaxial damage on chloride diffusion}

After the measurements of the gas permeability on virgin and cracked specimen, these 303 specimens were then saturated in basic solution in order to measure the chloride diffusion. 
The accumulation of chloride ions in the downstream compartment is shown as a function of

305 time for OC and HPC in Figure 10. The amount of chloride ions that had flowed through the 306 thickness of the concrete specimen was recorded and plotted versus time and for different 307 load level. Two distinct phases with respect to the change of chloride concentration are 308 acknowledged. The first is a phase where chloride ions are in the process of migrating through 309 saturated pores in concrete and hence have not yet reached the anode compartment. This 310 phase is normally called a transition period and the migration of chloride ions is under non steady-state conditions. It is apparent that transition period was dependent on load level and 312 on the concrete mixes. The second phase is called the steady-state period where the increase 313 of chloride concentration becomes constant with elapsed time, providing a constant flux of 314 chloride ions, the flux $\mathrm{J}$ is calculated with the constant slope of a regression line. These slopes 315 were used to calculate the diffusion coefficient of chlorides ions using Eq. (5). The time to 316 penetrate through the specimen is called lag time $\left(\mathrm{T}_{\text {lag }}\right)$, which is the intersection point of the 317 line with the $X$-axis [9]. The results showed that for virgin concrete the chloride diffusion 318 coefficient increased with the increase of the porosity, the average diffusion coefficients for 319 the virgin specimen, were $1,8810^{-12} \mathrm{~m}^{2} / \mathrm{s}$ for OC and $0,6710^{-12} \mathrm{~m}^{2} / \mathrm{s}$ for HPC. For the applied 320 load of $90 \% \mathrm{f}_{\mathrm{c}}$ for 2 hours, the diffusion coefficient were $5,7410^{-12} \mathrm{~m}^{2} / \mathrm{s}$ for OC and $1,2810^{-12}$ $321 \mathrm{~m}^{2} / \mathrm{s}$ for HPC. Figure 11 presents the variation of time lag versus the diffusion coefficient. 322 The results show that for virgin concrete $\mathrm{T}_{\text {lag }}$ of HPC are higher than for OC. A higher $\mathrm{T}_{\text {lag }}$ 323 may result from a lower porosity. This is an effect of the material. $\mathrm{T}_{\text {lag }}$ depends on the 324 porosity of concrete and chloride binding [36]. However, for cracked specimen it appears that $325 \mathrm{~T}_{\text {lag }}$ decreased with the diffusion coefficient $\mathrm{D}_{\mathrm{e}}$ increasing. A linear correlation was obtained between the diffusion coefficient $\mathrm{D}_{\mathrm{e}}$ and the time lag $\mathrm{T}_{\text {lag. }}$. It can be seen that the slope for

327 HPC is greater than for OC. This was due probably to chloride ion penetration from 328 microcracks to the virgin concrete, which was considered to occur more easily in OC concrete 
compared with HPC as OC porosity is higher than HPC porosity. This suggests that the effect

330 of cracking on the time it takes chloride to penetrate the sample is greater for OC than for 331 HPC.

332

333

\subsection{Increase chloride diffusion coefficient versus strain}

The chloride diffusion coefficients evolutions of OC and HPC versus a residual strain are reported in Fig. 12. It seems that the diffusion coefficient less sensitive than gas permeability to the residual deformation obtained. The variation of chloride diffusion coefficients begins for residual deformations in excess of $100 \mu / \mathrm{m}$ corresponding to loads greater than $70 \% \mathrm{f}_{\mathrm{c}}$ for OC and $80 \% \mathrm{f}_{\mathrm{c}}$ for HPC.

\subsection{Relationship between increase chloride diffusion coefficient and damage value}

The relative diffusivity of cracked concrete $D_{e}(d) / D_{e 0}$ is defined as the ratio between the diffusion coefficient of cracked concrete $\mathrm{D}_{\mathrm{e}}(\mathrm{d})$ and the diffusion coefficient of uncracked concrete $\mathrm{D}_{\mathrm{e} 0}$. It can be related to the damage variable "d". Figure 13 presents the evolution of relative diffusivity of cracked concrete with damage value assessed by the dynamic method. This evolution which is non material dependant is consistent with an increasing more marked for OC which has a diffusion coefficient of uncracked concrete larger than the HPC. The relative diffusivity of OC for the high load level is about 2.5 while it's about 1.9 for HPC. From Figure 13 the relationship between these two parameters can be expressed by a linear variation with a correlation coefficient $\mathrm{R}^{2}=0.94$ and also can be written as the exponential function with a correlation coefficient $\mathrm{R}^{2}=0.98$. This exponential function is similar to that obtained for the gas permeability with different empirical coefficients. This allows to develop an empirical relationship between these two transfer parameters, even if they are not corresponding to the same transport mechanisms. 


\subsection{Relationship between increase the gas permeability and chloride diffusion coefficient}

Gas permeability and diffusivity are governed by two transport modes. The variation of these two parameters depends on the microstructure of concrete and cracking that can be characterized by the damage. According to the equations presented in Figure 9 and Figure 13, we find that the gas permeability and diffusion coefficient show a same trend based on the damage variable. This allows us to establish a relationship between these two transfer parameters. Gas permeability is measured on a dry sample as the diffusion coefficient is measured on the same sample in saturated state by migration test under steady state condition. The results show that there is a linear relationship between the evolution of these two parameters depending on the damage variable, specific for each concrete type (Figure 14), with a correlation coefficient $\mathrm{R}^{2}=0.98$ for $\mathrm{OC}$ and $\mathrm{R}^{2}=0.99$ for HPC.

Figure 15 shows the variation of the $\mathrm{k}_{\mathrm{v}}(\mathrm{d}) / \mathrm{k}_{\mathrm{v} 0}$ according to the ratio $\mathrm{D}_{\mathrm{e}}(\mathrm{d}) / \mathrm{D}_{\mathrm{e} 0}$ for $\mathrm{OC}$ and HPC. The existence of a microcrack network seems to modify significantly the sustainability indicators. However, the influence is different for each concrete. It is observed that gas permeability is more sensitive to damage: in the case of $\mathrm{OC} \mathrm{k}_{\mathrm{v}}(\mathrm{d}) / \mathrm{k}_{\mathrm{v} 0}$ increases by a factor of 10 while $D_{e}(d) / D_{e} 0$ increases by a factor of 2.5 . For high-performance concrete $k_{v}(d) / k_{v 0}$ increases by a factor of 7 while $\mathrm{D}_{\mathrm{e}}(\mathrm{d}) / \mathrm{D}_{\mathrm{e} 0}$ increases by a factor of 1.9 . This tendency was already observed in previous studies, the gas permeability changes very significantly with the increase of damage level [8,10-13], while chloride penetration is much less affected by cracks [14-17].

It is noted that the relative permeability increases linearly with the relative diffusion coefficient, with a correlation coefficient $\mathrm{R}^{2}=0.98$ for $\mathrm{OC}$ and $\mathrm{R}^{2}=0.97$ for HPC. This relation could be assimilated to a no material dependant linear relationship. This result has to be verified with other materials tested with different curing history and test conditions. This linear relationship could be useful to avoid experimental test in the case of safety assessment 
of existing marine structures which are not so aged. Since the building of Vasco Gamma

381 Bridge in Lisbon (1995-1998), the durability criteria are requested for structures design in

382 Europe [37]: gas permeability and chloride diffusion coefficients are evaluated for non

383 damaged material before being used in the structure. For safety assessment of these structures,

384 only damaged gas permeability has to be measured to evaluate the relative diffusion 385 coefficient of cracked concrete and so the damaged diffusion coefficient. The gas 386 permeability measurement is not time consuming compared to the chloride migration test.

387 Moreover this test allows keeping a non contaminated concrete specimen which could be used 388 for others concrete characterisation: the coring is so limited. But this linear relationship 389 between relative gas permeability and relative diffusion coefficient has to be established with 390 other concrete mixing and also in the case of more advanced damage rate before being used 391 for safety assessment. Unfortunately this study covers a very limited damage rate: maximal d 392 value is about 0.15 .

393 The increase obtained for these two transfer parameters is more important for OC than for 394 HPC, this result confirms that micro cracking obtained with diffuse damage at same load level 395 impact on the transfer parameters for concrete which have higher porosities or higher crack 396 density as OC [38].

\section{4. Conclusions}

399 From the results presented in this paper it can be concluded that:

400 - The damage of concrete can be obtained using a uniaxial compression test. For loads 401 above $60 \% \mathrm{f}_{\mathrm{c}}$, the maximal strain $\varepsilon_{\max }$ and residual strain $\varepsilon_{\text {rés }}$ increase with increasing load 402 and time load for both concretes OC and HPC. This variation can be interpreted by the 403 existence of microcracks and their evolution according to the applied load.

404 - There is a linear relationship between the damage variable calculated with the modulus 405 obtained by the static method with the strength-strain curve and that calculated with the 
406 modulus measured by the dynamic method. This method is non destructive and very 407 useful by comparison with the static method but the modulus obtained are less 408 representative of the material. This linear relationship should be verify with other concrete 409 but could be very useful to get the static damage variable with the grindosonic apparatus.

410 - The intrinsic permeability coefficient $\mathrm{k}_{\mathrm{V}}$ of OC and HPC increased with the increase of the 411 residual strain, OC shows higher values. This can be explained by the gas flow through 412 the pores and additionally through cracks in the case of cracked concrete with diffuse 413 damage at the same load level.

414 - Results show that there is an exponential variation between the increase permeability $415 \quad \mathrm{k}_{\mathrm{v}}(\mathrm{d}) / \mathrm{k}_{\mathrm{v} 0}$ and damage variable " $\mathrm{d}$ ", for both types of concretes OC and HPC. There is a 416 also a single relationship between the ratio $D_{e}(d) / D_{e}$ and the damage variable " $d$ ".

417 - The diffuse damage obtained by uniaxial compression test in pre-peak affects the 418 diffusion of chloride ions. This damage causes an increase in the diffusion coefficient $\mathrm{D}_{\mathrm{e}}$ 419 and a decrease in the time lag $\mathrm{T}_{\text {lag. }}$. There is a linear correlation between these two 420 parameters; this relationship is specific for each of concrete type.

421 - The time lag reduction $\mathrm{T}_{\text {lag }}$ between virgin and most cracked concrete is more marked for 422 HPC which has a $\mathrm{T}_{\text {lag }}$ of virgin concrete higher than the $\mathrm{OC}$. This was due probably to 423 chloride ion penetration from microcracks to the virgin concrete, which was considered to 424 occur more easily in OC concrete compared with HPC as OC porosity is higher than HPC 425 porosity. This essentially means that the effect of cracking on $\mathrm{T}_{\text {lag }}$ is more important for 426 dense materials with a higher $\mathrm{T}_{\text {lag }}$ for the uncracked material.

427 - A linear correlation is obtained between intrinsic permeability coefficient $\mathrm{k}_{\mathrm{V}}$ and diffusion 428 coefficient $\mathrm{D}_{\mathrm{e}}$ depending on the damage variable, specific for each concrete type (OC and 429 HPC). 
- Gas permeability is more sensitive of concrete damage than chloride diffusion: in the case of OC $k_{v}(d) / k_{v 0}$ increases by a factor of 10 while $D_{e}(d) / D_{e}$ increases by a factor of 2.5 . For high-performance concrete $k_{v}(d) / k_{v 0}$ increases by a factor of 7 while $D_{e}(d) / D_{e 0}$ increases by a factor of 1.9 .

\section{References}

[1] T. Sugiyama, T.W. Bremner, Y. Tsuji, Determination of chloride diffusion coefficient and gas permeability of concrete and their relationship, Cement and Concrete Research 26 (5) (1996) 781-790.

[2] M. Maage, S. Helland, E. Poulsen, O. Vennesland, and J.E. Carl, Service life prediction of existing concrete structures exposed to marine environment, $A C I$ Materials Journal 93 (1996) 602-608.

[3] W.Y. Jung, Y.S. Yoon, Y.M Sohn, Predicting the remaining service life of land concrete by steel corrosion, Cement and Concrete Research 33 (2003) 663-677.

[4] W.M. Zhang, H.J. Ba., Accelerate life test of concrete in chloride environment, Journal of materials in civil Engineering 23 (3) (2011) 330-334.

[5] V. Picandet, A. Khelidj, H. Bellegou, Crack effect on gas and water permeability of concretes, Cement and Concrete Research 39 (2009) 537-547.

[6] Aldea, C., Shah, P., Karr, A., Effect of cracking on water and chloride permeability of concrete, Journal of materials in civil Engineering 11 (3) (1999) 181-187.

[7] Olga, GR., Doug Hooton, R., Influence of cracks on chloride ingress into concrete, ACI Materials Journal 100 (2) (2003) 120-126.

[8] C. Tognazzi, J,P Ollivier, M carcasses, J;M. Torrenti, Couplage fissurationdégradation chimique des matériaux cimentaires: premiers résultats sur les propriétés de transfert, in : Petit, Pijauder Cabot, Reynouard (Eds), Ouvrage Géomatériaux et interactions-Modélisations Multi-Echelles, Hermes, France, 1998, pp. 69-84.

[9] A. Djerbi, S. Bonnet, A. Khelidj, V. Baroghel-bouny, Influence of traversing crack on chloride diffusion into concrete, Cement and Concrete Research (38) (2008) 877-883.

[10] A. Kermani, Permeability of stressed concrete, Building Research and Information 19 (6) (1991) 362-365.

[11] T. Sugiyama, T.W. Bremner, T.A. Holm, Effect of stress on Gas permeability in concrete, ACI Materials Journal 93 (5) (1996) 443-450.

[12] V. Picandet, A Khelidj, G Bastian, Effect of axial compressive damage on gas permeability of ordinary and high-performance concrete, Cement and Concrete Research 31 (2001) 1525-1532. 
[13] M. Choinska, A. Khelidj, G. Chatzigeorgiou, G. Pijaudier-Cabot, Effects and interactions of temperature and stress-level related damage on permeability of concrete, Cement and Concrete Research, 37 (1) (2007), 79-88

[14] T. Sugiyama, Permeability of stressed concrete, Doctoral thesis, Dept. of Civil Engineering, University of new Brunswick, Canada, 1994.

[15] HR. Samaha, K.C. Hover, Influence of microcracking on the mass transport properties of concrete, ACI Materials Journal 89 (4) (1992) 416-424.

[16] M. Saito, H. Ishimori, Chloride permeability of concrete under static and repeated loading, Cement and Concrete Research 25 (4) (1995) 803-808.

[17] CC. Lim, N. Gowripalan, V. Sirivivatnanon, Microcracking and chloride permeability of concrete under uniaxial compression, Cement and Concrete Composite 22 (2000) 353-360.

[18] C. Zhou, K. Li, J. Han, Characterizing the effect of compressive damage on transport properties of cracked concretes, Materials and Structures,45 (2012) 381-292.

[19] F. Jacobs, Permeability to gas of partially saturated concrete, Magazine and Concrete Research 50, (2) (1998) 115-121

[20] S. Nagataki, Effect of heating condition on air permeability of concrete at elevated temperature, Transaction of the Japaneses Concrete Institute 10 (1980) 147-154.

[21] Méthodes recommandées pour la mesure des grandeurs associées à la durabilité, Proceedings of Journées Technique APC-AFREM, Durabilité des Bétons, France, 1998, pp. 121-124.

[22] C. Mazzotti, M. Savoia, Non linear Creep, Poisson's Ratio, and Creep-Damage interaction of Concrete in Compression, ACI Materials Journal 99 (5) (2002) 450457.

[23] J. Lemaitre, J. Dufailly, Damage measurements, Engineering Fracture Mechanics, 28 (1987) 643-661.

[24] J. Mazars, Application de la mécanique de l'endommagement au comportement non linéaire et à la rupture du béton de structure, Doctoral thesis, E.N.S.E.T., Université Pierre et Marie Curie, C.N.R.S., 1984

[25] R.J. Allison, Non-destructive determination of Young's modulus and its relationship with compressive strength, porosity and density, Geological Society of London Special Publication 29 (1987) 3-69.

[26] J.J. Kollek, The determination of the permeability of concrete to oxygen by the Cembureau method - a recommendation, Materials and Structures 22 (1989) 225230.

[27] R.K. Dhir, P.C. Hewlett, Y.N. Chan, Near surface characteristics of concrete: intrinsic permeability, Magazine of Concrete Research, 41(1989) 87-97. 
[28] L.J. Klinkenberg, The permeability of porous media to liquid and gases, Drilling and Production Practice, American Petroleum Institute, New York, (1941) 200-213.

[29] C. Andrade, Calculation of chloride diffusion coefficient in concrete from ionique diffusion measurements, Cement and Concrete Research 23 (3) (1993) 724-742.

[30] O. Truc, A new way for determining the chloride diffusion coefficient in concrete from steady state diffusion test, Cement and Concrete Research 30 (2000) 217-226.

[31] T. Luping, Chloride transport in concrete-Measurement and predictions, Doctoral thesis, Dept. of Building Materials, Chalmers University of Technology, Gothenburg, Sweden.

[32] M.M. Smadi, F.O. Slate, Microcracking of high and normal strength concretes under short and long term loadings, ACI Material Journal 86 (2) (1989) 117-127.

[33] S.P. Shah, S. Chandra, Critical Stress, Volume Change and Microcracking of Concrete, ACI Journal, Proceedings 65 (1968) 770-781.

[34] R.L. Carrasquilio, A.H. Nilson, F. Slate, Microcracking behavior of high strength Concrete Subject to Short Term Loading. Journal Proceedings, 78 (1981) 179-186.

[35] K.M. Nemati, P. Monteiro, K. Scrivener, Analysis of Compressive Stress-Induced Cracks in Concrete, ACI Material Journal, 95 (1998) 617-630.

[36] O. Coussy, R. Eymard, Non-linear binding and the diffusion-migration test, Transport in Porous Media, 53 (2003) 51-74.

[37] V. Baroghel-Bouny, Concrete design for structures with predefined service life durability control with respect to reinforcement corrosion and alkali-silica reaction state-of-the-art and guide for the implementation of a performance-type and predictive approach based upon durability indicators. English version of Documents Scientifiques et Techniques de l'AFGC (Civil Engineering French Association), 2004.

[38] C. Zhou , K. Li , X. Pang, Geometry of crack network and its impact on transport properties of concrete, Cement and Concrete Research 42 (2012) 1261-1272. 